\title{
Observations of flow and sediment entrainment on a large gravel-bed river
}

\author{
Peter R. Wilcock, ${ }^{1}$ Alan F. Barta, ${ }^{2}$ Conor C. Shea, ${ }^{3}$ G. Mathias Kondolf, ${ }^{4}$ \\ W. V. Graham Matthews, ${ }^{4}$ and John Pitlick ${ }^{5}$
}

\begin{abstract}
Constant-discharge reservoir releases on the Trinity River, California, provide an unusual opportunity to unambiguously relate flow and gravel entrainment on a large gravel-bed river. Bed shear stress $\tau_{0}$ was estimated using local observations of depthaveraged velocity. Gravel entrainment was measured using large tracer gravel installations. Lateral variability of $\tau_{0}$ is large, even for straight channels with simple, trough-like geometry. No simple relation exists between local and cross-section mean values of $\tau_{0}$. Fine grains (less than $8 \mathrm{~mm} ; 20-30 \%$ of the bed material) are transported at lower discharges than coarse grains. Scour to the base of the bed surface layer occurs at a dimensionless shear stress $\tau_{\mathrm{g}}^{*} \approx 0.035$, for $\tau_{\mathrm{g}}^{*}$ formed using local $\tau_{0}$ and the median grain size of the gravel portion of the bed. The dimensionless reference transport rate $W^{*}=0.002$, often used as a surrogate for the threshold of grain motion, occurs at nearly the same $\tau_{\mathrm{g}}^{*}$. At smaller $\tau_{\mathrm{g}}^{*}$, entrainment and transport rates decrease rapidly, becoming vanishingly small at $\tau_{\mathrm{a}}^{*} \approx 0.031$. Even at very small gravel transport rates, all sizes are transported, although the coarsest sizes are in a state of partial transport in which only a portion of the exposed grains are entrained. Both entrainment and cumulative transport observations suggest that maximum scour depth for plane-bed transport is slightly less than twice the surface layer thickness.
\end{abstract}

\section{Introduction}

The problem of predicting the critical river discharge $Q_{\mathrm{c}}$ that initiates sediment movement is of wide importance. Estimates of $Q_{\mathrm{c}}$ are needed to determine sediment transport rates, the frequency and duration of channel-forming flows, the dimensions of stable channels, and the occurrence of bed scour, armoring, downstream fining, and fine sediment infiltration or removal. Because $Q_{\mathrm{c}}$ depends on local channel properties, the entrainment problem is commonly posed in terms of a critical bed shear stress $\tau_{\mathrm{c}}$ for incipient motion, which may be defined as a function of sediment properties alone. For application, an estimate of $\tau_{\mathrm{c}}$ must be coupled with an estimate of the bed shear stress $\tau_{0}$ as a function of discharge, channel geometry, and hydraulic roughness.

A number of factors limit the accuracy of estimates of $Q_{\mathrm{c}}$ in large gravel-bed rivers, preventing routine application from readily observable properties of the channel geometry and sediment. One problem is uncertainty in determining values of $\tau_{c}$ from the bed size distribution. Ideally, $\tau_{c}$ should be estimated as a function of easily measurable properties of the bed sediment, particularly its size distribution, but problems of method, measurement, and accuracy give rise to uncertainty in

\footnotetext{
${ }^{1}$ Department of Geography and Environmental Engineering, The Johns Hopkins University, Baltimore, Maryland.

${ }^{2}$ Intermountain Research Station, U.S. Forest Service, Boise, Idaho.

${ }^{3}$ Parsons Brinckerhoff, Inc., Baltimore, Maryland.

${ }^{4}$ Center for Environmental Design Research, University of California, Berkeley.

${ }^{5}$ Department of Geography, University of Colorado, Boulder.

Copyright 1996 by the American Geophysical Union.

Paper number 96WR01628.

0043-1397/96/96WR-01628\$09.00
}

the prediction of $\tau_{\mathrm{c}}$ for mixed-size sediments [Wilcock, 1988, 1992a]. Another obstacle is the typically large spatial variability of both flow and grain size in large gravel-bed rivers. In simple equilibrium transport fields, such as flumes or small rivers with uniform geometry, spatial averages of $\tau_{0}$ and grain size may be used to estimate $\tau_{\mathrm{c}}$ and $Q_{\mathrm{c}}$. The spatial variation of flow and grain size in larger rivers ensures that this approach will be inaccurate locally; the net effect of local error may be quite large, particularly when transport occurs in part of the channel even though the section-average $\tau_{0}$ is less than $\tau_{\mathrm{c}}$. Error in either $\tau_{\mathrm{c}}$ or $\tau_{0}$ is compounded by the steep, nonlinear relation between $\tau_{0}$ and the sediment transport rate, which can produce large errors in calculated transport rate from small errors in either $\tau_{c}$ or $\tau_{0}$.

A third obstacle to predicting $Q_{\text {c }}$ concerns measurement logistics and accuracy: in large rivers it is generally not possible to measure flow and sediment entrainment with sufficient accuracy at a temporal and spatial resolution appropriate to the elementary physics of the problem. Clearly, both spatial variability and measurement problems contribute directly to uncertainty in developing predictive relations for $\tau_{c}$.

Finally, the stochastic nature of gravel transport ensures that no single value of $Q_{\mathrm{c}}$ exists. Grain motion near $\tau_{\mathrm{c}}$ occurs in sporadic, brief events, separated by relatively long periods of immobility. The range of grain sizes typically present on a gravel bed, combined with the spatial variability in grain size and bed topography, ensures that uniform entrainment will not occur at a single $Q$ but will consist of individual grain displacements whose frequency varies spatially and increases with $Q$. This local variability points to aspects of grain entrainment with importance beyond defining a threshold for measurable transport. In particular, the proportion of the bed surface mobilized during a flow and the entrained proportion of individual size fractions exposed on the bed surface control sediment 
exchange between the transport, bed surface and subsurface, and therefore changes in the bed surface size distribution and size-selective erosion or deposition.

We measured local flow and gravel entrainment on two reaches of the Trinity River, a large gravel-bed river in northern California. Unusually favorable field conditions were provided by three trial reservoir releases which had nearly constant discharge, were scheduled in advance, and were immediately preceded and followed by very low discharges permitting direct observation and sampling of the gravel bed. The entrainment produced by each release could be determined without ambiguity by measuring the proportion of grains removed from large tracer gravel installations. This new approach provides estimates of the size and scour depth of entrained sediment and the proportion of the bed surface mobilized. The local shear stress $\tau_{01}$ over the tracer gravels was determined from observations of depth-averaged velocity, providing a basis for generalizing our results through comparison with observations made in flumes or small rivers.

Incipient gravel motion is often represented as the value of $\tau_{0}$ that produces a small reference transport rate [e.g., Parker et al., 1982; Wilcock, 1988; Wilcock and Southard, 1988; Ashworth and Ferguson, 1989; Kuhnle, 1992]. To provide a comparison with our entrainment observations, we measured gravel transport rates using gravel traps and bed load samplers. Although the reference-transport estimate of $\tau_{c}$ is clearly defined and measurable, it provides no indication of the proportion of the bed contributing to the transport. The tracer gravel observations provide such a measure, and a comparison of tracer entrainment and transport rates demonstrates the degree of bed mobilization associated with different fractional transport rates.

\section{Critical Shear Stress and Bed Surface Mobilization}

There has been considerable discussion and some disagreement about appropriate values for $\tau_{c}$ in coarse mixed-size sediments. It is well known that $\tau_{\mathrm{c}}$ increases directly with grain size for unisize sediments in the gravel size range. The same relation has also been shown to hold for the median grain size $D_{50}$ of many mixed-size sediments [Wilcock, 1992a]. An exception occurs for gravel beds with a large proportion of sand, giving a strongly bimodal size distribution and apparently reducing $\tau_{c 50}$ relative to unimodal size mixtures [Wilcock, 1993].

The critical shear stress $\tau_{\mathrm{ci}}$ for individual grain sizes $D_{\text {, }}$ within mixed-size sediment depends strongly on the relative grain size within the mixture (e.g., $\left.D_{t} / D_{50}\right)$. Size-dependent hiding, exposure, and resistance cause $\tau_{\mathrm{ci}}$ to be reduced for larger grains and increased for smaller grains relative to comparable values of $\tau_{c}$ in unisize sediment. Much of the recent work (and disagreement) has focused on whether relative size effects entirely cancel absolute size effects, producing values of $\tau_{\mathrm{ci}}$ that are independent of grain size [e.g., Parker et al., 1982; Andrews, 1983; Carling, 1983; Komar, 1987; Wilcock and Southard, 1988; Ashworth and Ferguson, 1989; Church et al., 1991; Wilcock, 1993] (see also recent review by Gomez [1995]). Discrepancy among $\tau_{c i}$ results may be attributed to the spatial and temporal variability of gravel transport [Gomez, 1983; Iseya and Ikeda, 1987; Kuhnle and Southard, 1988; Pitlick, 1988; Wathen et al., 1995], to the difficulty of measuring values of $\tau_{0}$ appropriate to the observed entrainment, and to differences in the methods used to estimate $\tau_{\mathrm{ci}}$ [Wilcock, 1988].

Estimates of $\tau_{c}$ are typically based on observations of gravel transport and therefore provide little guidance regarding the proportion of the bed surface that is entrained, the mobilized proportion of each size fraction, and the depth of grain exchange between the bed and transport. The depth of grain exchange is needed to define an active layer thickness for models of selective transport and to estimate transport rates from observations of the cumulative displacement of tracers. The mobilized proportion of each size on the bed surface influences both the rate and size distribution of sediment exchange between bed and transport, which controls the evolution of the bed surface size distribution and therefore the rates of selective transport, downstream fining, and armoring. The proportion of the bed surface entrained also determines the quantity of finer sediments that may be introduced into, or removed from, the bed subsurface when coarse surface clasts are entrained. This is the application underlying the field work described here: removal of infiltrated fine sediment was one goal of the trial reservoir releases.

For sediments with a wide range of grain sizes (exceeding a factor of $\sim 16$ ), it has been observed that a range of transport exists over which the transport rates of the coarser fractions can be orders of magnitude smaller than those of the finer fractions, when each is scaled by its presence in the bed [Wilcock, 1992b; Wilcock and McArdell, 1993; Wathen et al., 1995]. Wilcock and McArdell [1993] proposed that the relative decrease in transport rate with increasing grain size can be attributed, in part, to the fact that a portion of the coarser grains on the bed surface remain immobile over the duration of a flow. This condition, termed partial transport, has importance regarding not only fractional transport rates but any process (such as selective deposition or flushing of subsurface fines) that depends on the proportion of the bed surface entrained. Confirmation of a state of partial transport requires direct observation of the mobilized proportion of the grains exposed on the bed surface. Such observations have been made in the laboratory using the unusual artifice of a sediment bed in which each size fraction was painted a different color [Wilcock and McArdell, 1993]. This work confirmed the existence of a state of partial transport and demonstrated its dependence on grain size and flow strength [McArdell and Wilcock, 1994].

The tracer gravel method described in this paper provides an opportunity to estimate the mobilized proportion of the bed surface and the depth of sediment exchange. Because transport rates were also measured, we can compare tracer entrainment and transport rates to determine the degree of bed mobilization associated with different transport rates.

\section{Study Site}

The Trinity River drains $7640 \mathrm{~km}^{2}$ of steep, dissected terrain in the Klamath Mountains of northwestern California. The basin is mostly forested, although much of it has been clearcut since 1950. Runoff from the uppermost $1860 \mathrm{~km}^{2}$ of the basin was impounded by Trinity Dam (and its reregulating reservoir, Lewiston Dam) beginning in 1961, as part of the U.S. Bureau of Reclamation Central Valley project. Our flow and transport observations were made along two reaches, Poker Bar and Steelbridge, located $15 \mathrm{~km}$ and $20 \mathrm{~km}$ downstream of Lewiston Dam, respectively (Figure 1 ). Overall, the river has a broadly sinuous pool-and-riffle channel, although both study reaches have nearly straight channels with simple, gradually varying topography. Most observations were focused on one section within each reach (PB2 and SB3C, Figure 2), and the sections immediately upstream and downstream. 


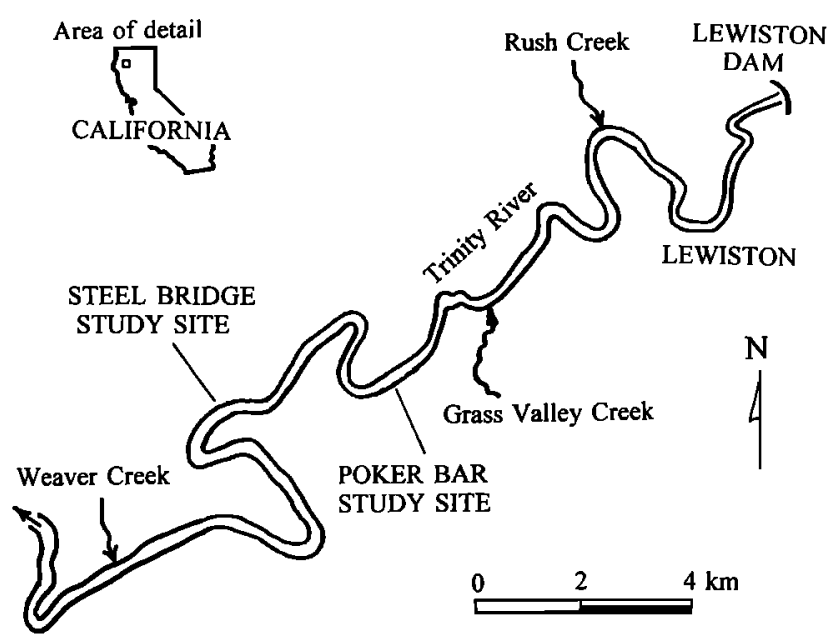

Figure 1. Location map of the Trinity River downstream of Trinity and Lewiston Dams.

At Poker Bar the channel is $\sim 35 \mathrm{~m}$ wide and rectangular in section, with a deeper trough along the right bank (Figure 2a). The river banks are nearly vertical and composed of finegrained material $(<0.5 \mathrm{~mm})$ deposited along the margins of the much wider active channel that existed before the Trinity and Lewiston Dams were closed in 1963. Extremely low discharges following dam closure permitted vegetation to become established within the former active channel and the banks have apparently been built during occasional tributary floods carrying high concentrations of fine sediment [Wilcock et al., this issue]. Bankfull discharge for the present channel is approximately $75 \mathrm{~m}^{3} / \mathrm{s}$ (Figure $2 \mathrm{a}$ ).

At Steelbridge the river is split into two channels by an island that developed from vegetation encroachment and finesediment accretion on a midchannel bar deposited after dam closure. The study section is in the smaller right channel, which carries a nearly constant $32 \%$ of the discharge for all flows observed by us. Here, the channel is $\sim 20 \mathrm{~m}$ wide with steep, fine-grained banks similar to those at Poker Bar (Figure 2b).

The bed at the study sections is composed of sand, gravel, and cobble. Material finer than $8 \mathrm{~mm}$ composes between 20 and $30 \%$ of the bed, forming a matrix that completely fills the interstices of the larger framework grains. The fine material is derived from decomposed granitic terrain drained by tributaries downstream of the dam. It has a distinctly lighter color and nearly all of it is between $0.5 \mathrm{~mm}$ and $8 \mathrm{~mm}$ in size. By filling coarse pore spaces the fine material limits habitat for aquatic invertebrates and juvenile fish and is thought to limit salmonid spawning success by blocking fry emergence from the bed. Sediment finer than $0.5 \mathrm{~mm}$ is transported through as wash load, except for the small fraction deposited on the channel banks at high stage. A number of factors, including sampling logistics, the distinction between matrix and framework bed material, and a difference in ecological role, suggest that material finer than $8 \mathrm{~mm}$ may be treated as a separate population from the gravel and cobble. By local convention, which we

\section{(a) Poker Bar}
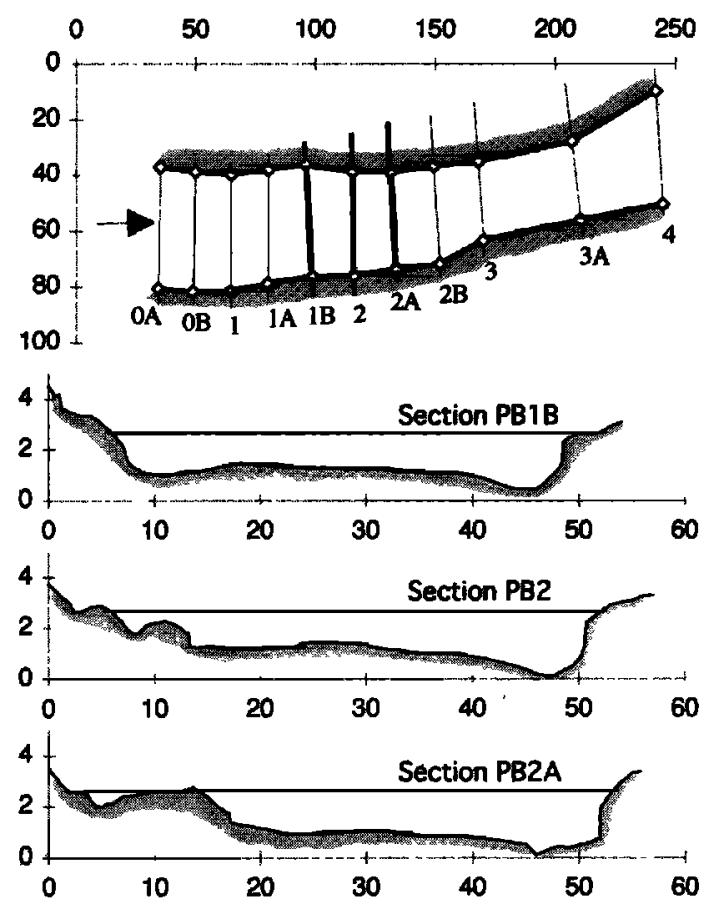

(b) Steelbridge
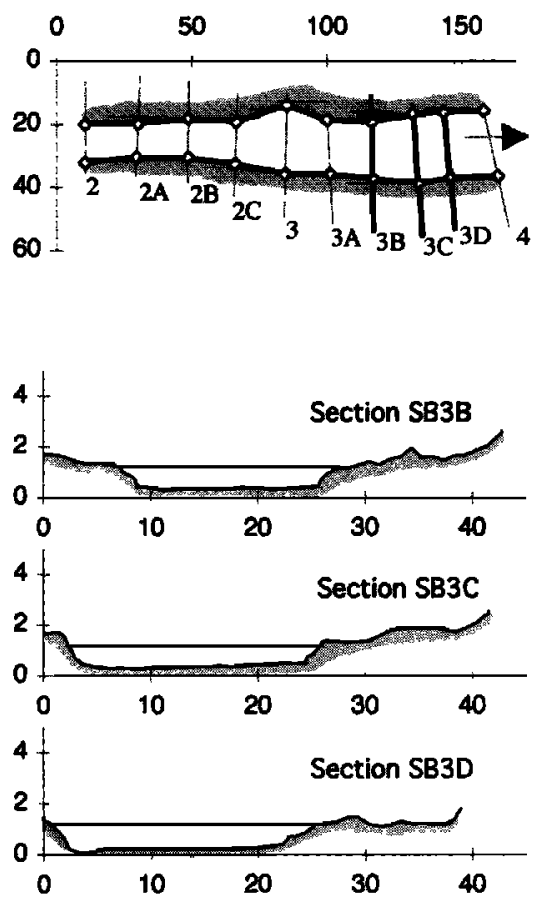

Figure 2. Map of surveyed channel boundaries and cross sections for the (a) Poker Bar and (b) Steelbridge study reaches. Cross-section topography shown for sections PB2 and SB3C and adjacent sections. All lengths in meters. The plotted water level corresponds to $Q=76 \mathrm{~m}^{3} / \mathrm{s}$. A small channel carrying less than $1 \%$ of flow exits the left side of the Poker Bar reach between PB1B and PB2. At Steelbridge, flow is divided into two channels separated by an island; the study reach is the right channel, which carries approximately $32 \%$ of the discharge. SB4 marks the downstream end of the island. Cross sections are not to scale. The channels are generally wide, shallow, and trough-like with gradually varying topography. 

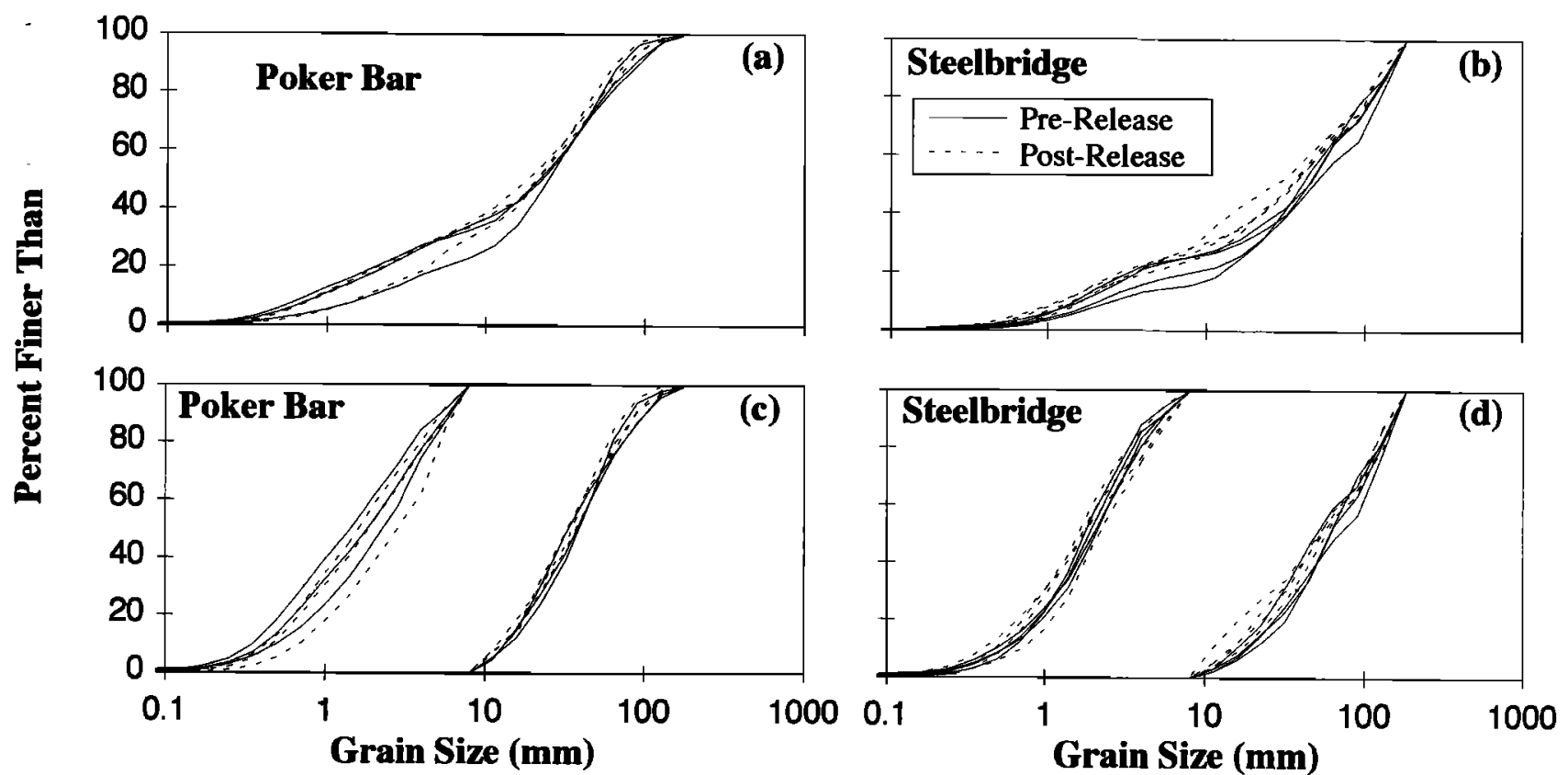

Figure 3. Cumulative grain-size distributions for bulk samples taken in 1992 along sections PB2 and SB3C. (a) and (b) Entire size distribution; (c) and (d) distributions truncated at the ad hoc sand/gravel boundary of $8 \mathrm{~mm}$. Samples were taken before and after the 1992 release, giving six samples at Poker Bar (total of 1427 $\mathrm{kg}$ ) and eight samples at Steelbridge (total of $1123 \mathrm{~kg}$ ). The size distributions show only limited spatial variability, primarily in the total proportion and size distribution of the sand. The trial release had only a small effect on the proportion of sand and negligible effect on the gravel size distribution.

follow here as a matter of convenience, sand and gravel are defined as material finer or coarser than $8 \mathrm{~mm}$, respectively.

Bed-material size distributions, based on large bulk samples taken before and after the 1992 release, are given for both study sections in Figure 3. Figures $3 a$ and $3 b$ present the cumulative size distribution for the entire bed; Figures $3 \mathrm{c}$ and $3 \mathrm{~d}$ present the size distributions truncated at $8 \mathrm{~mm}$. The samples were taken by working a $50-\mathrm{cm}$ oil drum into the bed and extracting the material within. Before-and-after samples were taken at three locations along PB2 $(26,28.5$, and $30 \mathrm{~m}$, Figure 2a) with sample depth between 27 and $40 \mathrm{~cm}$, which is $3-5$ times the thickness of $D_{90}$ (size for which $90 \%$ of the distribution is finer). Along SB3C, four pairs of samples were taken $(11,12.5,14.5$, and $16.5 \mathrm{~m}$, Figure $2 \mathrm{~b}$ ) with sample depths between 19 and $29 \mathrm{~cm}$, which is $2-3$ times the thickness of $D_{90}$ at that section. Because turbidity within the drum prevented observation of the bed during sampling, no attempt was made to sample separately the bed surface and subsurface. Pebble counts were also made before and after the releases along each section shown in Figure 2, typically with 100 counts per section. At PB2, 200 counts were made between 24 and $32 \mathrm{~m}$, and 100 counts were made between 15 and $24 \mathrm{~m}$ and between 32 and $37 \mathrm{~m}$. At SB3C, 200 counts were made between 3 and $18 \mathrm{~m}$, and 100 counts were made between 11 and $16.5 \mathrm{~m}$.

From bulk samples the median size $D_{50}$ of the bed is $22 \mathrm{~mm}$ at $\mathrm{PB} 2$ and $37 \mathrm{~mm}$ at SB3C using the entire size distribution and $36 \mathrm{~mm}$ and $58 \mathrm{~mm}$, respectively, for the size distribution truncated at $8 \mathrm{~mm}$. Values of $D_{50}$ from pebble counts over the same part of the section were $29 \mathrm{~mm}$ at PB2 and $44 \mathrm{~mm}$ at SB3C. These values are only slightly larger than the bulk sample values, suggesting that surface coarsening is relatively weak at the study sections. Values of $D_{90}$ for pebble counts and bulk samples are nearly the same at both sections.
Little decrease in sand proportion occurred over the duration of the releases (Figure 3), a result of the quantity of sand present in the bed upstream of the study sections and the limited duration of the releases [Wilcock et al., this issue]. The sand size distributions show some spatial variability, whereas the gravel distributions are relatively constant at each section.

\section{Flow Observations}

Releases from Lewiston Dam were made from May 28 to June 2, 1991, June 10 to 19, 1992, and April 13 to May 4, 1993 (Figure 4). At our study sections we observed a constant discharge for 3 days in $1991\left(76.0 \mathrm{~m}^{3} / \mathrm{s}\right), 4$ days in $1992\left(164 \mathrm{~m}^{3} / \mathrm{s}\right)$, and 2 days in $1993\left(80 \mathrm{~m}^{3} / \mathrm{s}\right.$, Table 1$)$.

During the releases, velocity and depth were measured from rafts moved along the study sections using a network of climbing ropes (see Wilcock et al. [1995] for detail). Most observations were made at sections PB2 and SB3C, with additional transects made at the sections immediately upstream and downstream. Velocity was measured with Price AA current meters. Except in 1992 at Poker Bar, the meters were mounted on wading rods up to $3 \mathrm{~m}$ long. The rods were held off the bow with the rod base on the channel bottom. All observations in a vertical profile were made without moving the rod to ensure accurate relative placement of the meter. Greater flow depths in 1992 at Poker Bar required that the current meters be mounted on a cable with a 100 -lb weight and moved in the vertical with a crane-and-reel assembly. Cable mounting permits less spatial control, particularly in the horizontal, than rod mounting.

Complete velocity transects were made on at least two different days across sections PB2 and SB3C in 1991 and 1992 when tracer gravels were in place and across section PB2 in 


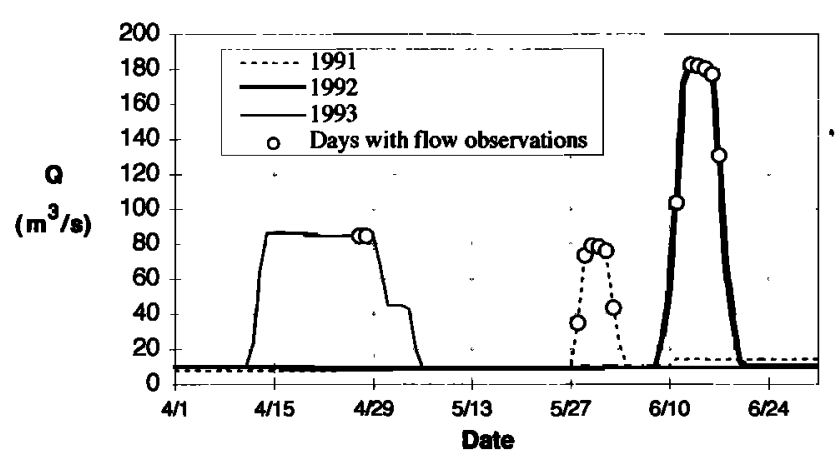

Figure 4. Daily mean discharge at USGS gage at Lewiston, California during March through June, 1991, 1992, and 1993. Gage is $1.3 \mathrm{~km}$ downstream of Lewiston Dam. Discharge values at study reaches are slightly different due to upstream storage. Ramping flows on rising and falling limbs include a 12-hour period of constant discharge, during which additional flow observations were made in 1991 and 1992. Discharge was 9 or $10 \mathrm{~m}^{3} / \mathrm{s}$ immediately preceding and following each reservoir release.

1993 when gravel traps were in place. The mean channel hydraulics and sampling plan for each of these transects are summarized in Table 1.

The point velocity $u$ was found, in general, to follow a logarithmic variation with elevation throughout the water depth, as is typically observed for wide open channel flow with only grain-scale roughness and flow depth much greater than the bed roughness. Estimates of $\tau_{01}$ were made using the flow depth $h$, the depth-integrated velocity $U$, and an estimate of bed roughness $z_{0}$ in a flow resistance relation. An evaluation of alternative methods for estimating $\tau_{01}$ demonstrated that for the flow conditions we observed, this method provides more precise estimates than using either a single near-bed velocity observation or the slope of the near-bed vertical velocity profile [Wilcock et al., 1994; Wilcock, 1996]. The relation used here is the depth-integrated form of the log law applied throughout the flow depth

$$
\frac{U}{u_{*}}=\frac{1}{\kappa} \ln \left(\frac{h}{e z_{0}}\right)
$$

where $u_{*}$ is bed shear velocity $\left(=\left[\tau_{01} / \rho\right]^{1 / 2}\right), \rho$ is the water density, $\kappa$ is von Karman's constant, taken to be 0.4 , and $e$ is the base of the natural logarithms. The resulting $\tau_{01}$ estimates were found to have the same mean value but more precision than estimates of $\tau_{01}$ made from the slope of the semilogarithmic velocity profile for 22 replicate profiles with at least six observations in the lower half of the flow. Although the latter estimate has lower precision, it does not require an independent estimate of bed roughness. Therefore it was used to provide an estimate of $z_{0}$ as a function of visual estimates of $D_{90}$ at each station. The relation $z_{0}=0.095 D_{90}$ was found to minimize the squared difference in $u_{*}$ between the two estimates for 75 velocity profiles. This result is almost identical to $z_{0}=0.1 D_{84}$, found by Whiting and Dietrich [1990] in a more detailed study of boundary shear stress and roughness.

Values of $\tau_{01}$ and unit discharge $q=U h$ (normalized by the section mean $Q / B$, where $B$ is channel width) are given in Figure 5 for the 1991 and 1992 releases. Also shown on Figure 5 are the locations of the tracer gravels and gravel traps. Observations for individual days are shown with light lines, and the mean values carried forward in the analysis are shown by heavy lines with symbols. Measurement accuracy is suggested by the relatively small variation between plots of $q$ for different days with the same discharge (Figures $5 \mathrm{a}$ and $5 \mathrm{~b}$ ) and by the fact that the largest difference in total discharge calculated for periods with constant stage was always $<5 \%$ (based on three groups of five $Q$ observations and one group of two). Somewhat greater scatter is evident in the cable-mounted observations made at Poker Bar in 1992, although even in that case, it is evident that the error is smaller than lateral variation in $q$ or $\tau_{0}$.

The lateral distribution of flow is somewhat more uniform at PB2 than SB3C, where flow becomes increasingly concentrated in a central portion of the channel as discharge increases (Figure $5 b)$. A large lateral variability is evident in $\tau_{01}$. The variation of $\tau_{01}$ is nearly threefold within the central $15 \mathrm{~m}$ of the nearly rectangular SB3C channel (neglecting the regions within approximately $4 \mathrm{~m}$ of the banks). This lateral variability makes it clear that estimates of local gravel entrainment and transport, as well as total transport through the section, require local flow observations, even in straight channels with simple geometry.

Figure 6 provides an approximate comparison between section-averaged and local values of mean velocity, flow depth,

Table 1. Summary of Velocity Observations Along Primary Study Sections With Tracer Gravels or Gravel Traps in Place

\begin{tabular}{|c|c|c|c|c|c|c|c|c|c|}
\hline $\begin{array}{l}\text { Cross } \\
\text { Section }\end{array}$ & Date & $\begin{array}{c}\text { Discharge, } \\
\mathbf{m}^{3} / \mathbf{s}\end{array}$ & $\begin{array}{c}\text { Mean } \\
\text { Flow } \\
\text { Depth, } \\
\text { m }\end{array}$ & $\begin{array}{c}\text { Mean } \\
\text { Flow } \\
\text { Velocity, } \\
\mathrm{m} / \mathrm{s}\end{array}$ & $\begin{array}{c}\text { Mean } \\
\text { Energy } \\
\text { Slope, } \\
\times 10^{-3}\end{array}$ & $\begin{array}{c}\text { Number } \\
\text { of } \\
\text { Stations }\end{array}$ & $\begin{array}{c}\text { Readings } \\
\text { per } \\
\text { Station }\end{array}$ & $\begin{array}{c}\text { Spacing } \\
\text { Between } \\
\text { Stations, } \\
\text { m }\end{array}$ & $\begin{array}{c}\text { Current } \\
\text { Meter } \\
\text { Mounting }\end{array}$ \\
\hline PB2 & May 29, 1991 & 68.2 & 1.49 & 1.21 & 0.91 & 15 & $14-16$ & 2 & $\operatorname{rod}$ \\
\hline PB2 & May 30, 1991 & 75.6 & 1.57 & 1.27 & 1.20 & 14 & $8-9$ & 3 & rod \\
\hline PB2 & June 13,1992 & 164 & 2.49 & 1.71 & 0.84 & 12 & $4-5$ & 3 & cable \\
\hline PB2 & June 14,1992 & 164 & 2.49 & 1.71 & 0.84 & 12 & $3-4$ & 3 & cable \\
\hline PB2 & June 15,1992 & 164 & 2.49 & 1.71 & 0.84 & 13 & $4-5$ & 3 & cable \\
\hline PB2 & April 27, 1993 & 80.0 & 1.59 & 1.33 & 1.17 & 14 & 4 & 3 & rod \\
\hline PB2 & April 28, 1993 & 80.0 & 1.59 & 1.33 & 1.17 & 17 & 4 & 3 & rod \\
\hline SB3C & May 31, 1991 & 76.0 & 0.76 & 1.35 & 3.34 & 12 & $7-8$ & 2 & rod \\
\hline SB3C & June 1, 1991 & 76.0 & 0.76 & 1.35 & 3.34 & 12 & $7-8$ & 2 & rod \\
\hline SB3C & June 14,1992 & 164 & 1.61 & 1.42 & 1.20 & 10 & 4 & 2 & $\operatorname{rod}$ \\
\hline SB3C & June 16,1992 & 164 & 1.61 & 1.42 & 1.20 & 11 & 4 & 2 & rod \\
\hline
\end{tabular}



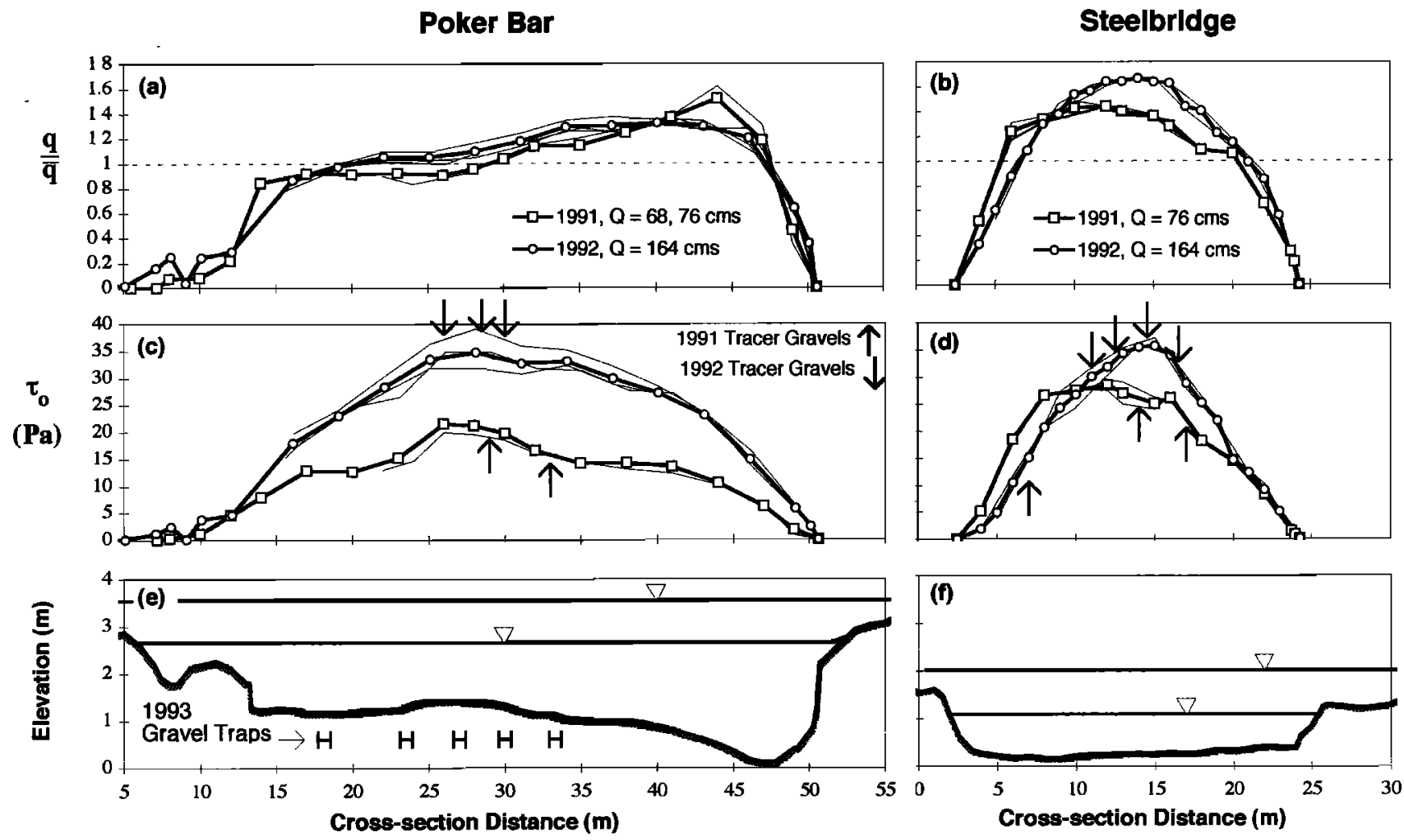

Figure 5. Lateral distribution of (a) and (b) unit discharge and (c) and (d) local bed shear stress at sections PB2 and SB3C. Unit discharge calculated as $U h$ and normalized by section mean unit discharge $Q / B$. Shear stress calculated using (1). In each case, complete traverses of velocity and depth observations were made on two or three different days. Mean values are shown as heavy lines with circles or squares; daily values are shown as light lines. At Poker Bar in 1991 the discharge varied slightly between the two days with observations; the heavy line is $Q=76 \mathrm{~m}^{3} / \mathrm{s}$ and the light line is $Q=68 \mathrm{~m}^{3} / \mathrm{s}$. Lateral variation of flow is much larger than daily differences at a constant $Q$. Flow in the shallower and narrower Steelbridge channel is more concentrated in a central zone that shifts with $Q$. Discharge in the overbank regions is negligible.

unit discharge, and $\tau_{0}$. Here, local values are averages over the central portion of the section containing tracer gravels. Section-average calculations use the flow area above the main channel because flow in the heavily vegetated overbank regions had negligible velocity. Section-averaged flow depth $H$ is calculated as $A / B$, where $A$ is the flow area of the channel. Section-averaged $\tau_{0}$ is calculated as $\rho g H S$, where $S$ is the slope of the energy grade line calculated using section-averaged $U$ and the observed water surface elevation at the main section and the sections immediately upstream and downstream. Section-averaged $\tau_{0}$ is also calculated by integrating $\tau_{01}$ across the section. These values agree fairly closely with those calculated as $\rho g H S$ (Figures $6 \mathrm{~g}$ and $6 \mathrm{~h}$ ), suggesting that only a weak lateral component exists in the flow. The anomalous large value of $\rho g H S$ at $Q=76 \mathrm{~m}^{3} / \mathrm{s}$ at SB3C is probably related to uncertainty in the values of mean channel velocity at each section because the flow is beginning to exceed the bank level and some leakage of flow from the left to the right channel may occur over the island.

Local velocity increases with $Q$ at both sites, although the increase relative to the section average is much larger at SB3C, where the mean velocity shows only a weak increase with $Q$ (Figures 6a and 6b), probably as the result of a backwater from the flow merging with the larger left channel at SB4. A similar pattern is evident in the local unit discharge: both $q_{1}$ and $\partial q_{1} / \partial Q$ are larger at SB3C (Figures 5, 6e and 6f). At both sites, local values of $\tau_{0}$ are larger than section-averaged values and increase more rapidly with discharge. At PB2 the mean local value increases to a value $30 \%$ greater than the section mean, while at SB3C the mean local value is $65 \%$ larger at the highest flow observed. Clearly, if estimates of grain entrainment over the central portion of the channels were based on the sectionaveraged $\tau_{0}$, the entrainment would be grossly underestimated. Differences in estimated $Q_{\mathrm{c}}$ of the order of a factor of 2 are possible at PB2, with even larger differences at SB3C. Given the very strong nonlinear relation between $\tau_{01}$ and gravel transport, such errors in estimating $Q_{\mathrm{c}}$ could produce errors of several orders of magnitude in estimated transport rates.

\section{Gravel Movement}

\section{Tracer Gravels}

Our primary observations of grain entrainment were made using large tracer gravel installations on the main study sections. After surveying the bed elevation, a metal cylinder was inserted into the bed, all sediment down to the bottom of the sampler was excavated (similar to the method of McNeil and Ahnell [1960]), and its size distribution was determined. In 1991 we used a sampler with a diameter of $30 \mathrm{~cm}$ and sample depths up to $30 \mathrm{~cm}$, giving sample sizes between 13 and $30 \mathrm{~kg}$. We enlarged the sample size in 1992 by using a sampler with a diameter of $59 \mathrm{~cm}$ and sampling as deep as $40 \mathrm{~cm}$ (Table 2). 


\section{Poker Bar}
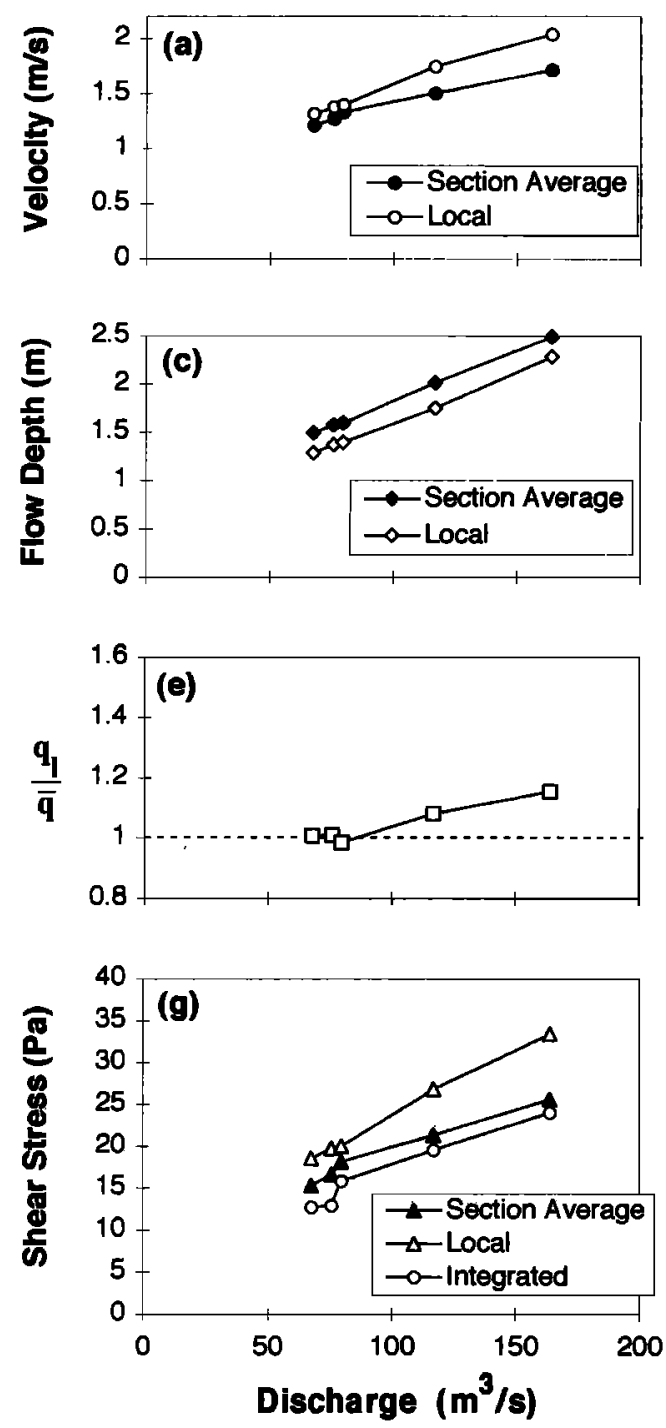

Steelbridge
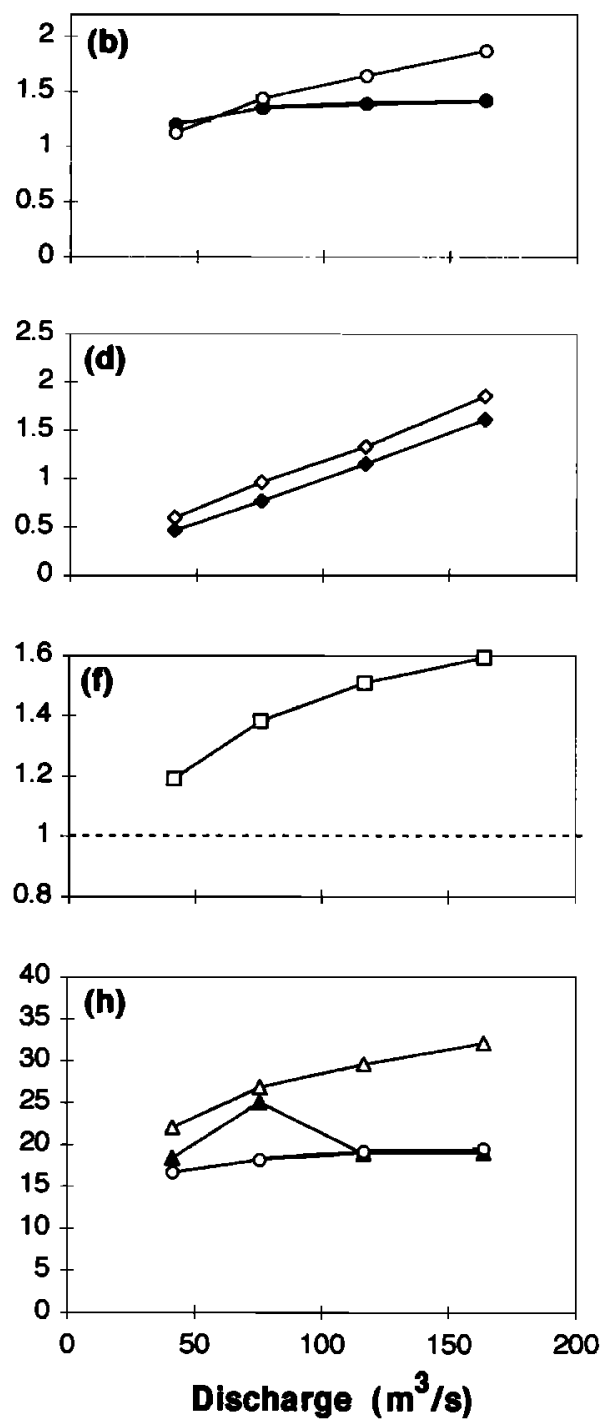

Figure 6. Variation with $Q$ of (a) and (b) velocity, (c) and (d) flow depth, (e) and (f) unit discharge, and (g) and $(\mathrm{h})$ bed shear stress at sections PB2 and SB3C. Both section average and local values shown. Local values are averages over the tracer gravels (lateral station 23.5-35.5 m for PB2; 10-17 m at SB3C; see Figure 5). Section-averaged values exclude overbank flow. Section averaged $\tau_{0}$ is calculated using $\rho \mathrm{gHS}$; also shown is mean $\tau_{0}$ obtained by integrating local $\tau_{0}$ across each section.

These samples contained between 112 and $281 \mathrm{~kg}$ and provide our best measure of the bed size distribution.

The sediment was returned to the cylinder as a homogeneous mix and filled to the presample elevation. All sizes larger than $16 \mathrm{~mm}$ were replaced with distinctly marked tracer grains, matching the number and shape of grains in each $1 / 2 \phi$ size class. During the 1991 release we replaced the entire bulk sample with pure white quartz clasts. During the 1992 release we replaced a representative portion of the sampled sediment with painted grains. The tracer clasts were placed in the center of the bulk sample location, using a 25 -cm-diameter plastic bucket with the bottom removed, and the annulus was filled with the balance of the bulk sample. This approach was used to facilitate recovery of all of the remaining tracer clasts after the release.

When replacing the tracer sediment, we attempted to repli- cate the bulk density of the natural bed, as could be approximately determined by walking over tracers and undisturbed material. Nonetheless, the sampling disturbance raises the possibility that entrainment of tracer and undisturbed grains might differ. Although we cannot independently confirm that the structure and entrainment of the tracers mimicked that of the natural bed, several lines of evidence suggest that the tracer entrainment is representative. First, active spawning has been observed in the study reaches in the 5 years between the start of this study and the previous gravel-transporting flow in 1986, suggesting that the bed should be relatively well-mixed with little internal structure. This is supported by our observation of little or no armoring at the study sections. Second, tracer entrainment in both 1991 (partial surface mobilization) and 1992 (complete surface mobilization) was consistent with visual estimates of entrainment made possible by the fact that $a$ 
Table 2. Tracer Gravel Installations

\begin{tabular}{lcccc}
\hline & $\begin{array}{c}\text { Sample } \\
\text { Depth } d_{\text {s }} \\
\text { cm }\end{array}$ & $\begin{array}{c}\text { Sample } \\
\text { Mass, } \\
\text { kg }\end{array}$ & $\begin{array}{c}\text { Pebble Count } \\
D_{90}, \mathbf{m m}\end{array}$ & $\begin{array}{c}\text { Exchange } \\
\text { Depth } d_{\mathbf{x}} \\
\mathrm{cm}\end{array}$ \\
\hline 1991 PB2-29 & 9 & 14 & 100 & 0.18 \\
1991 PB2-33 & 14 & 28 & 100 & 0.28 \\
1991 SB3C-7 & 3 & 22 & 120 & $\mathbf{0 . 1 8}$ \\
1991 SB3C-14 & 5 & 15 & 120 & 0.75 \\
1991 SB3C-17 & 7 & 13 & 120 & 0.63 \\
1991 SB3D-8 & 14 & 22 & 112 & 5.3 \\
1991 SB3D-10 & 13 & 23 & 112 & 5.5 \\
1991 SB3D-13 & 9 & 14 & 112 & 3.3 \\
& & & & \\
1992 PB2-26 & 39 & 271 & 85 & 12.9 \\
1992 PB2-28.5 & 35 & 238 & 85 & 11.9 \\
1992 PB2-30 & 27 & 196 & 85 & 10.5 \\
1992 SB3C-11 & 25 & 146 & 100 & 11.0 \\
1992 SB3C-12.5 & 20 & 112 & 100 & 10.4 \\
1992 SB3C-14.5 & 21 & 132 & 100 & 8.8 \\
1992 SB3C-16.5 & 19 & 120 & 100 & $10^{*}$ \\
\hline
\end{tabular}

${ }^{*}$ No scour observed, tracers buried to a depth of $\approx D_{90}$.

dark stain develops on the exposed side of surface grains, so that mobilized grains typically appear clean and lighter in color. From these observations we assume, but cannot prove, that the tracer entrainment was comparable to local entrainment of undisturbed material. Application of this tracer method to channels with an armored, imbricated bed would be more difficult, unless a means were found to replicate the surface structure.

After the trial releases, we resampled the tracers to determine the number and size of immobile grains, from which the entrained mass was determined. The depth of bed scour, or exchange depth $d_{\mathrm{x}}$, was calculated as the sample depth multiplied by the mass proportion of grains entrained (Table 2). Because grain size and sample depth vary from sample to sample, comparison among samples requires a consistent basis for scaling $d_{x}$, for which the thickness of the bed surface layer is appropriate. Using $D_{90}$ as the scaling length, the scaled exchange depth is calculated as

$$
\frac{d_{\mathrm{x}}}{D_{90}}=\frac{M_{\mathrm{e}}}{M_{1}} \frac{d_{\mathrm{s}}}{D_{90}}
$$

where $M_{\mathrm{e}}$ is the mass of grains entrained, $M_{\mathrm{t}}$ is the total mass of tracer gravels, and $d_{\mathrm{s}}$ is the sample depth.

A fractional exchange depth $d_{\mathrm{xi}}$ is calculated as the entrained proportion of grains of each size times the sample depth. Scaled by $D_{\mathbf{9 0}}$, this is

$$
\frac{d_{\mathrm{x} 1}}{D_{90}}=\frac{\left(M_{t}\right)_{\mathrm{e}}}{\left(M_{t}\right)_{\mathrm{t}}} \frac{d_{\mathrm{s}}}{D_{90}}
$$

where $\left(M_{t}\right)_{\mathrm{e}}$ and $\left(M_{i}\right)_{t}$ are the entrained and total mass of grains of size $i$. Because $\left(M_{\mathrm{t}}\right)_{\mathrm{t}}\left(D_{90} / d_{\mathrm{s}}\right)$ approximates the mass of grains of size $i$ in the surface layer, values of $d_{\mathrm{x} i} / D_{90}$ less than one may also be interpreted as the mobilized proportion of surface grains of each size.

To account for differences in grain size from sample to sample, $d_{\mathrm{x}} / D_{90}$ is plotted in Figure $7 \mathrm{a}$ as a function of the Shields parameter $\tau_{\mathrm{g}}^{*}\left(=\tau_{01}\left[\left(\rho_{\mathrm{s}}-\rho\right) g D_{\mathrm{g}}\right]^{-1}\right.$, where $\rho_{\mathrm{s}}$ and $\rho$ are the sediment and water density, $g$ is acceleration of gravity, and $D_{\mathrm{g}}$ is the median size of the gravel portion of the bed). $D_{\mathrm{g}}$ is used in preference to $D_{50}$ of the entire bed because the sand content (and therefore $D_{50}$ ) may be expected to be more transient than that of the gravel. The effect of using $D_{50}$ of the entire bed in $\tau^{*}$ would be a relatively uniform shift of the points in Figure 7 to the right by roughly $60 \%$.

Direct comparison of the entrainment produced by the two releases implies that both flows were of sufficient duration to mobilize nearly all entrainable grains, so that a longer release would not produce measurably larger values of $d_{x} / D_{90}$. Although we cannot demonstrate that such a limit was reached, the mobilized proportion of individual fractions has been observed to asymptotically approach a limiting value in a laboratory study of grain entrainment [McArdell and Wilcock, 1994; P. R. Wilcock and B. W. McArdell, Partial transport of a sand/ gravel sediment, submitted to Water Resources Research, 1996].

Scaled exchange depth $d_{\mathrm{x}} / D_{90}$ shows a consistent increase with $\tau_{\mathrm{g}}^{*}$ (Figure 7a). If $d_{x^{\prime}} / D_{90}$ is assumed to increase rapidly for $\tau_{\mathrm{g}}^{*}$ just above a threshold $\tau_{\mathrm{th}}^{*}$ at which $d_{\mathrm{x}} / D_{90}=0$, and asymptotically approach a limiting value of $d_{\mathrm{x}} / D_{90}$ at large $\tau_{\mathrm{g}}^{*}$, an appropriate function is

$$
\frac{d_{\mathrm{x}}}{D_{90}}=a\left(1-\frac{\tau_{\mathrm{th}}^{*}}{\tau^{*}}\right)^{b}
$$

For $\tau_{\mathrm{th}}^{*}=0.031$, values of $a=1.7$ and $b=0.26$ minimize the sum of squared differences between (4) and the six $1992 \mathrm{ob}-$ servations in Figure 7a. This suggests a limiting scour depth on

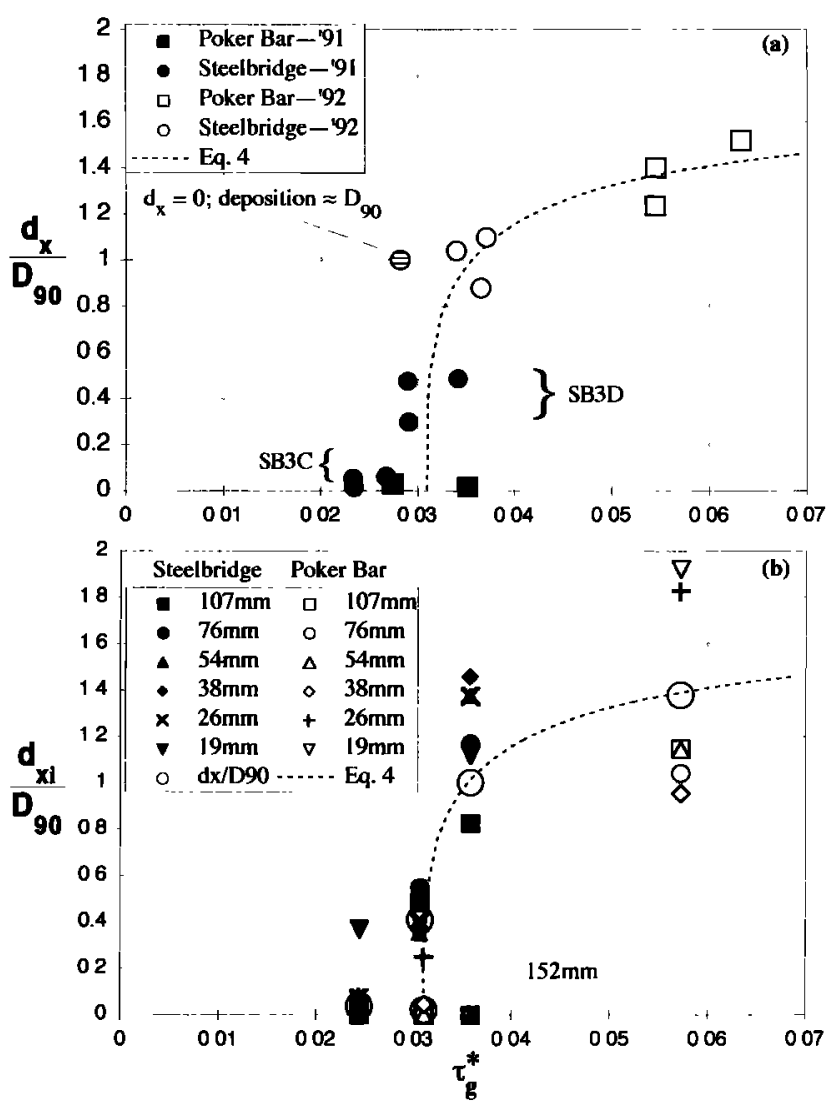

Figure 7. Exchange depth as a function of $\tau_{\mathrm{g}}^{*}$ (a) total exchange depth $d_{x}$, scaled by $D_{90}$, for all tracer gravels. (b) fractional exchange depth $d_{\mathrm{x}}$, scaled by $D_{90}$. Samples for each section and flow are combined in Figure $7 \mathrm{~b}$. The curve in Figure 7a is (4); the same curve is shown for reference in Figure $7 \mathrm{~b}$. A value of $d_{\mathrm{x}} / D_{90}=1$ corresponds to $\tau_{\mathrm{g}}^{*} \approx 0.035$. Some size dependence is evident in Figure $7 \mathrm{~b}$, particularly at the largest $\tau_{\mathrm{g}}^{*}$, with $d_{\mathrm{x} i} / D_{90}$ increasing with the inverse of $D_{\mathrm{i}}$. 
Table 3. Poker Bar Bed Load Sampling

\begin{tabular}{|c|c|c|c|c|c|c|c|c|c|}
\hline Date & $\begin{array}{c}\text { Discharge, } \\
\mathrm{m}^{3} / \mathrm{s}\end{array}$ & Station & $\begin{array}{c}\text { Total } \\
\text { Number of } \\
\text { Samples }\end{array}$ & $\begin{array}{c}\text { Total } \\
\text { Sample } \\
\text { Duration }\end{array}$ & $\begin{array}{c}\text { Gravel } \\
\text { Transport } \\
\text { Rate, } \\
\mathrm{g} / \mathrm{ms}\end{array}$ & $\begin{array}{c}\text { Sand } \\
\text { Transport } \\
\text { Rate, } \\
\text { g/ms }\end{array}$ & $\begin{array}{l}\text { Number of } \\
\text { Censored } \\
\text { Samples }\end{array}$ & $\begin{array}{c}\text { Censored } \\
\text { Gravel } \\
\text { Transport } \\
\text { Rate, } \\
\text { g/ms }\end{array}$ & $\begin{array}{c}\text { Censored } \\
\text { Sand } \\
\text { Transport } \\
\text { Rate, } \\
\text { g/ms }\end{array}$ \\
\hline \multirow[t]{6}{*}{ April 27-30, 1993} & 80 & 18.1 & 1 & 68 hours & 0.0004 & $\ldots$ & .. & ... & $\cdots$ \\
\hline & 80 & 23.5 & 1 & 68 hours & 0.0055 & $\cdots$ & $\ldots$ & $\ldots$ & $\ldots$ \\
\hline & 80 & 27 & 1 & 44 hours & 0.0046 & $\ldots$ & $\ldots$ & $\cdots$ & $\ldots$ \\
\hline & 80 & 30.0 & 1 & 68 hours & 0.0012 & $\ldots$ & $\ldots$ & $\ldots$ & $\cdots$ \\
\hline & 80 & 33.3 & 1 & 68 hours & 0.0107 & $\ldots$ & $\ldots$ & $\ldots$ & $\ldots$ \\
\hline & 80 & mean & 5 & 313.5 hours & 0.0045 & $\ldots$ & $\ldots$ & $\ldots$ & $\ldots$ \\
\hline $4 / 29 / 93$ & 80 & 19 & 2 & $8 \mathrm{~min}$ & $\ldots$ & 2.6 & $\ldots$ & $\ldots$ & $\ldots$ \\
\hline $4 / 29 / 93$ & 80 & 22 & 2 & $4 \mathrm{~min}$ & $\ldots$ & 24.8 & $\ldots$ & $\ldots$ & $\ldots$ \\
\hline $4 / 29 / 93$ & 80 & 25 & 2 & $4 \mathrm{~min}$ & $\ldots$ & 7.2 & $\ldots$ & $\ldots$ & $\ldots$ \\
\hline $4 / 29 / 93$ & 80 & 28 & 2 & $4 \min$ & $\cdots$ & 11.0 & $\cdots$ & $\cdots$ & $\cdots$ \\
\hline \multirow[t]{2}{*}{$4 / 29 / 93$} & 80 & 31.5 & 2 & $4 \mathrm{~min}$ & $\ldots$ & 24.9 & $\ldots$ & $\ldots$ & $\ldots$ \\
\hline & 80 & mean & 10 & $24 \mathrm{~min}$ & $\cdots$ & 14.1 & 6 & $\cdots$ & 8.4 \\
\hline $6 / 11 / 92$ & 103 & 20.1 & 6 & $12 \mathrm{~min}$ & 63.1 & 21.8 & 2 & 32.1 & 22.1 \\
\hline $6 / 11 / 92$ & 103 & 25.1 & 5 & $10 \mathrm{~min}$ & 4.0 & 45.2 & 3 & 1.8 & 40.7 \\
\hline \multirow{2}{*}{$6 / 11 / 92$} & 103 & 31.1 & 6 & $12 \mathrm{~min}$ & 2.1 & 75.4 & 2 & 1.9 & 32.4 \\
\hline & 103 & mean & 17 & $34 \mathrm{~min}$ & 24.2 & 47.6 & 7 & 3.6 & 31.7 \\
\hline \multirow{4}{*}{ June 12-16, 1992} & 164 & 20.1 & 12 & $24 \mathrm{~min}$ & 53.1 & 16.3 & 6 & 47.9 & 14.6 \\
\hline & 164 & 25.1 & 17 & $34 \mathrm{~min}$ & 72.4 & 90.4 & 9 & 41.1 & 52.4 \\
\hline & 164 & 30.1 & 31 & $62 \mathrm{~min}$ & 165.9 & 101.2 & 15 & 168.4 & 66.5 \\
\hline & 164 & mean & 60 & $120 \mathrm{~min}$ & 118.0 & 82.3 & 30 & 106.1 & 51.9 \\
\hline
\end{tabular}

the order of $1.7 D_{90}$ for plane-bed transport. A mean exchange depth of $d_{x} / D_{90} \approx 1.0$, or scour to the base of the bed surface layer, occurs at $\tau_{\mathrm{g}}^{*} \approx 0.035$, which is similar to many estimates of the dimensionless shear stress for incipient motion of the median size of mixed size sediment [Wilcock, 1992a, 1993]. The threshold between negligible grain entrainment and entrainment of most of the bed surface occurs over a narrow range of $\tau_{\mathrm{g}}^{*}$ of the order of $10-15 \%$.

For all cases with $d_{x} / D_{90}>0.1$ (SB3D in 1991, SB3C and PB2 in 1992), all sizes are entrained and fractional exchange depths fall within a factor of 2 , with the very largest fractions tending to have the smallest entrainment (Figure 7b). In 1992 at $\mathrm{SB} 3 \mathrm{C}$, sizes larger than $90 \mathrm{~mm}\left(\approx D_{72}\right)$ are in a state of partial transport $\left(d_{\mathrm{xi}} / D_{90}<1\right)$, whereas all finer sizes and $d_{\mathrm{x}} / D_{90}$ take values $\geq 1$. In 1992 at PB2, sizes larger than $32 \mathrm{~mm}$ $\left(\approx D_{60}\right)$ fall below $d_{x} / D_{90}$, whereas the finest two fractions have $d_{\mathrm{xi}} / D_{90}>1.8$. In 1991, the finest sizes observed at PB2 $(26 \mathrm{~mm})$ and at SB3C $(19 \mathrm{~mm})$ show weak partial transport $\left(0.2<d_{x i} / D_{90}<0.4\right)$, whereas all the coarser sizes are essentially immobile and $d_{\mathrm{x}} / D_{90}<0.1$. In 1991, $\tau_{01}$ at SB3D was slightly larger than at SB3C, giving $0.25<d_{x} / D_{90}<0.5$ (Figure 7a), and grains of all sizes finer than $D_{98}$ were moved.

The 1991 discharge of $Q=76 \mathrm{~m}^{3} / \mathrm{s}$ produced very little entrainment (all $d_{\mathrm{x}} / D_{90}<0.5$, most $d_{\mathrm{x}} / D_{90}<0.1$ ), whereas in $1992, Q=164 \mathrm{~m}^{3} / \mathrm{s}$ entrained the bed to a depth of roughly one surface layer or greater $\left(0.8<d_{x} / D_{90}<1.6\right)$ and mobilized all sizes up to $128 \mathrm{~mm}\left(D_{98}\right.$ at SB3C). These observations support a direct specification of the discharge needed to mobilize the bed surface, although this estimate is specific to our study reach and comes at the expense of extensive field work, the logistics of which depended on a prescheduled hydrograph with a simple rectangular shape.

\section{Transport Rates}

Gravel transport rates were measured at $Q=80 \mathrm{~m}^{3} / \mathrm{s}$ in 1993 using five wooden boxes buried flush with the streambed across PB2. The boxes were $80 \mathrm{~cm}$ long, $12 \mathrm{~cm}$ wide, and 10.5 $\mathrm{cm}$ deep and extended across $15 \mathrm{~m}$ of section (Figure 5 and Table 3). Sand was visibly in motion within the traps, so an unknown proportion was swept downstream and the boxes are assumed to act as efficient traps only for grains coarser than 8 $\mathrm{mm}$. The traps were first visited 14 days after the release began, at which time all traps were less than half full. The volume and grain size of trapped material were visually estimated, and the boxes were swept clean. Sediment continued to accumulate in the boxes until the end of the release, providing a second sample with a duration of 68 hours. The accumulated sediment was then removed by hand, weighed, and sieved. The accumulation rates from both sample periods were comparable, but only the second period is used here because the mass and size distribution of the trapped sediment were measured directly.

The gravel transport rates in 1993 were uniformly very small, with a mean transport rate of $0.0045 \mathrm{~g} / \mathrm{ms}$ (Table 3 ). The catch included one clast in the $64-90.5 \mathrm{~mm}$ size class and from five to more than 300 grains in the smaller size classes. Although the largest of the five samples is $\mathbf{3 0}$ times the smallest, there is no obvious lateral trend in the transport rates and much of the trap-to-trap variability may be attributed to the very small transport rates and the fact that the sample size is sensitive to the presence or absence of individual large clasts whose mass is on the order of the total for each trap. As a result, we use the aggregate transport for all five traps. As discussed below, the measurement of such small transport rates proves very useful in estimating the relation between gravel transport rate and $\tau_{01}$.

Transport rates were also measured with Helley-Smith samplers in 1992 and 1993. A sampler with a $15.2-\mathrm{cm}$ orifice was used in 1992. Because of the weight of the sampler and the large water depth and velocity the sampler was deployed from a crane-operated cable mounted on a wooden raft. It was not always possible to directly observe the sampling. Samples were collected during the peak discharge of $164 \mathrm{~m}^{3} / \mathrm{s}$ and during a 12-hour steady flow of $103 \mathrm{~m}^{3} / \mathrm{s}$ on the rising limb of the hydrograph. A sampler with a 3-inch $(7.62 \mathrm{~cm})$ orifice was used 


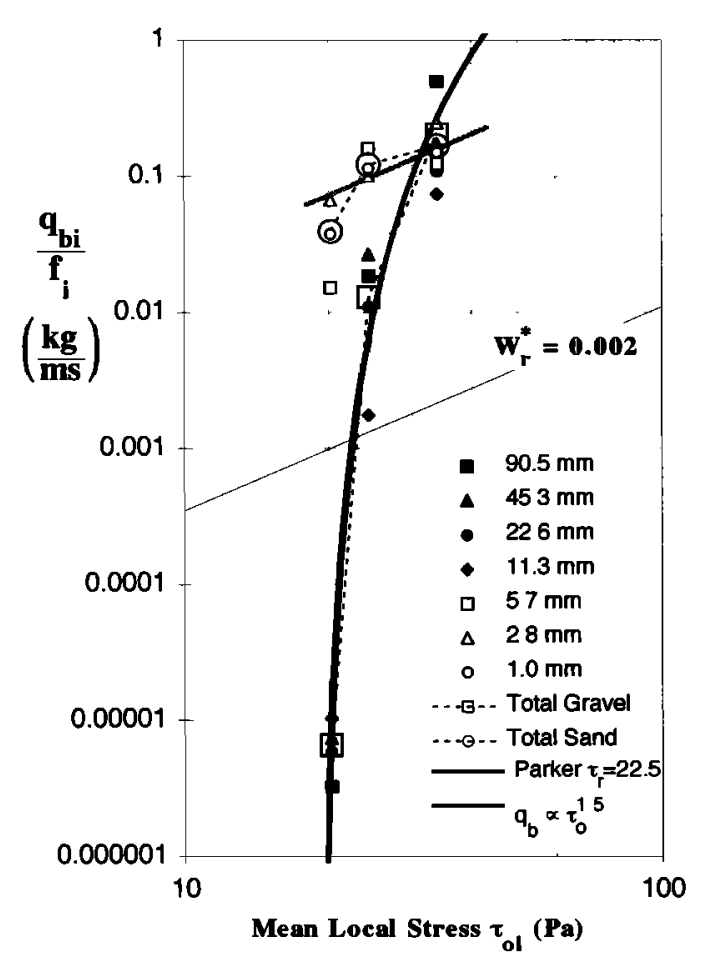

Figure 8. Fractional transport rates as a function of mean local bed shear stress over the central portion of PB2. Gravel trap data used for $D_{\mathrm{i}}>8 \mathrm{~mm}$ at $\tau_{0}=20 \mathrm{~Pa}$; Helley-Smith samples used for remainder. For individual locations, $\tau_{01}$ varies from the mean value shown by $\pm 3.0 \mathrm{~Pa}$ or less. Transport rates for individual locations given in Table 3. Reference transport line is $W_{\mathrm{r}}=0.002$. Parker [1979] transport relation shown with $\tau_{\mathrm{r}}=22.5 \mathrm{~Pa}$, which corresponds to $\tau_{\mathrm{r}}^{*}=0.039$ using gravel $D_{50}$. Comparison with Figures 7 suggests that the reference transport rate is associated with $d_{\mathrm{x}} / D_{90} \approx 1$ and partial transport of the coarser portions of the bed surface.

in 1993. The lighter sampler and smaller flow depths permitted the sampler to be deployed on a rigid rod, and the collection of all samples was directly observed. Results are presented here for samples made across the same $15-\mathrm{m}$ portion of PB2 that incorporates the gravel traps. To provide some measure of the possible oversampling (through bed scooping) or undersampling (when the base of the sampler is not flush with the bed surface) to which the Helley-Smith sampler is susceptible, the Helley-Smith transport rates were recalculated using approximately one-half of the samples, excluding the largest $25 \%$ and smallest $25 \%$ of the observed transport rates for each station. These values are presented as "censored transport rates" on Table 3.

For the Helley-Smith samples the ratio of maximum to minimum station gravel transport rate is approximately 25 for $Q=$ $103 \mathrm{~m}^{3} / \mathrm{s}$ and 3.6 for $164 \mathrm{~m}^{3} / \mathrm{s}$; for sand transport rates, the ratios are 10 for $Q=80 \mathrm{~m}^{3} / \mathrm{s}, 2.6$ for $Q=103 \mathrm{~m}^{3} / \mathrm{s}$ and 5.4 for $164 \mathrm{~m}^{3} / \mathrm{s}$. These are typical values for the spatial and temporal variability of gravel transport [Kuhnle and Southard, 1988; Pitlick, 1988; Gomez et al., 1989; Wathen et al., 1995]. In lieu of a statistical analysis of the relatively small number of samples, we assume no better than order-of-magnitude accuracy in the mean transport rates reported on Table 3 , based on the variability in transport from station to station and between total and censored samples. The least confidence is associated with the observations at $Q=103 \mathrm{~m}^{3} / \mathrm{s}$ and the sand transport at $Q=80 \mathrm{~m}^{3} / \mathrm{s}$, which are based on the smallest number of samples. Despite the large variation from sample to sample, we place somewhat greater confidence in the very small aggregate transport rates for the gravel traps because of their long duration and greater sampling width.

Total and fractional transport rates for each flow are summarized on Figure 8. Transport rate is plotted as a function of the mean $\tau_{01}$ over the sampled width. Different relations are evident for the total gravel and sand transport rates. At the smallest flow, sand transport exceeds that of gravel by 4 orders of magnitude. Gravel transport rate increases far more rapidly than that of sand, so that the two transport rates are comparable at the highest flow observed. For individual fractions within the sand and gravel, fractional transport rates differ by 1 order of magnitude or less and overlap only at $Q=164 \mathrm{~m}^{3} / \mathrm{s}$, for which the total sand and gravel transport rates are nearly identical.

The gravel transport rates are well matched by the Parker [1979] transport relation, which is a power approximation of the Einstein relation at low shear stresses. In the units of Figure 8, this relation is

$$
q_{\mathrm{b}}=\frac{\tau_{0}^{15}}{17.8}\left(1-0.85 \frac{\tau_{\mathrm{r}}}{\tau_{\mathrm{ol}}}\right)^{45}
$$

where $\tau_{\mathrm{I}}$ is the reference shear stress that produces a small reference transport rate and serves as a surrogate for the critical shear stress $\tau_{\mathbf{c l}}$. The reference transport rate is given as $W_{\mathrm{r}}^{*}=0.002$, where $W^{*}=\left[q_{\mathrm{b}}(\mathrm{s}-1) g\right] /\left[\rho_{\mathrm{s}} u_{*}^{3}\right], s$ is $\rho_{\mathrm{s}} / \rho$, taken to be 2.7 , and $\rho_{\mathrm{s}}$ is the sediment density, taken to be 2700 $\mathrm{kg} / \mathrm{m}^{3}$. For the specified values of $\mathrm{s}$ and $\rho_{\mathrm{s}}, W_{\mathrm{r}}^{*}$ is given in the units of Figure 8 as $q_{\mathrm{b}}=10^{-5} \tau_{0}^{1.5} ; \tau_{\mathrm{r}}$ is the only parameter in (5) requiring specification, and $\tau_{\mathrm{r}}=22.5 \mathrm{~Pa}$ is fitted to the higher-quality 1993 gravel trap observations (Figure 8). Because of the very steep form of (5) at small transport rates the value of $\tau_{r}$ is insensitive to the measured value of transport rate, as long as it is smaller than the reference transport. (For the same reason, $\tau_{\mathrm{r}}$ is relatively insensitive to the choice of $W_{\mathrm{r}}^{*}$, as long as it is small.) With the fitted $\tau_{\mathrm{r}}$, the resulting transport relation fits the larger 1992 gravel transport rates very well (Figure 8); $\tau_{\mathrm{r}}=22.5 \mathrm{~Pa}$ corresponds to $\tau_{\mathrm{g}}^{*}=0.039$, which falls within a narrow range of values found to represent $\tau_{\mathrm{r}}^{*}$ for the median size of a wide range of mixed-size sediments [Wilcock, 1992a].

A transport relation for sand is difficult to demonstrate because all observed transport rates are much larger than the reference transport rate. The total sand transport is consistent with a $3 / 2$ power relation between $q_{b}$ and $\tau_{0}$ (Figure 8 ), as would be expected for fully mobilized transport at large values of $\tau_{0} / \tau_{\mathrm{c}}$ [Yalin, 1977; Parker and Klingeman, 1982; Wilcock and McArdell, 1993].

\section{Comparison of Entrainment and Transport Rates}

Comparison of fractional entrainment $d_{\mathrm{xi}} / D_{90}$ and transport rates $q_{\mathrm{b}} / f_{\text {, at }}$ PB2 may be made by plotting each as a function of grain size (Figure 9). Fractional entrainment rates for SB3C are also shown on Figure 9a for comparison, although no observations of $q_{\mathrm{bi}}$ were made. At PB2, the tracer observations at $Q=76 \mathrm{~m}^{3} / \mathrm{s}$ and the gravel trap observations at $Q=80$ $\mathrm{m}^{3} / \mathrm{s}$ show that transport rates of all sizes are comparable, but very small, and little tracer entrainment occurs for any size. For $Q=164 \mathrm{~m}^{3} / \mathrm{s}$, gravel $q_{\mathrm{b} 1} / f_{\mathrm{i}}$ are within a factor of 3 for all sizes (Figure $9 \mathrm{~b}$ ) and $d_{\mathrm{xi}} / D_{90}$ are within a factor of 2 (Figure $9 \mathrm{a}$ ). 
The degree of entrainment associated with different transport rates is of particular interest regarding $\tau_{\text {ri }}$, which is determined as the value of $\tau_{0}$ producing a small reference transport rate, but serves as a surrogate for incipient motion conditions. The value of $\tau_{\mathrm{r}}=22.5 \mathrm{~Pa}$ gives $\tau_{g}^{*}=0.039$, corresponding to an exchange depth $d_{\mathrm{x}} / D_{90} \approx 1.15$ (Figure 7a) and is associated with entrainment of all sizes, with some partial transport evident for the coarsest fractions (Figure 7.b). This is an interesting and useful result. Two entirely different measures of incipient motion (the reference transport rate and mean scour to a depth of $\approx D_{90}$ ) are shown to occur at nearly the same flow. At $\tau_{0} / \tau_{\mathrm{ri}}$ of 0.85 to 0.9 , both entrainment and transport rates for the gravel fractions drop to essentially zero, as suggested by the form of the Parker [1979] transport relation (5). In the region $0.85<\tau_{0} / \tau_{\mathrm{ri}}<1.0$, a state of partial transport exists, and both $d_{\mathrm{x}} / D_{90}$ and $q_{\mathrm{b} i} / f_{\mathrm{i}}$ increase very rapidly with $\tau_{0}$.

A more direct comparison between entrainment and transport rate may be made if transport is expressed as a cumulative mass per unit width ( $\Sigma q_{\mathrm{b}}=q_{\mathrm{b}} T$, where $T$ is flow duration). This is plotted on Figure 10 as a function of fractional entrainment per unit area $E_{\mathrm{ai}}$; both $\Sigma q_{\mathrm{bi}}$ and $E_{\mathrm{ai}}$ are scaled by $f_{\mathrm{i}}$. The curves shown on Figure 10 correspond to the variation with $\tau_{0}$ of $d_{\mathrm{x}} / D_{90}$ and $q_{\mathrm{b}}$ given in (4) and (5), respectively (Figures 7a and 8$). E_{\mathrm{a}}$ is calculated using (4) with $\tau_{\mathrm{th}}^{*}=0.031$, giving $d_{\mathrm{x}} / D_{90}$ as a function of $\tau^{*}$, from which $E_{\mathrm{a}}$ is calculated as
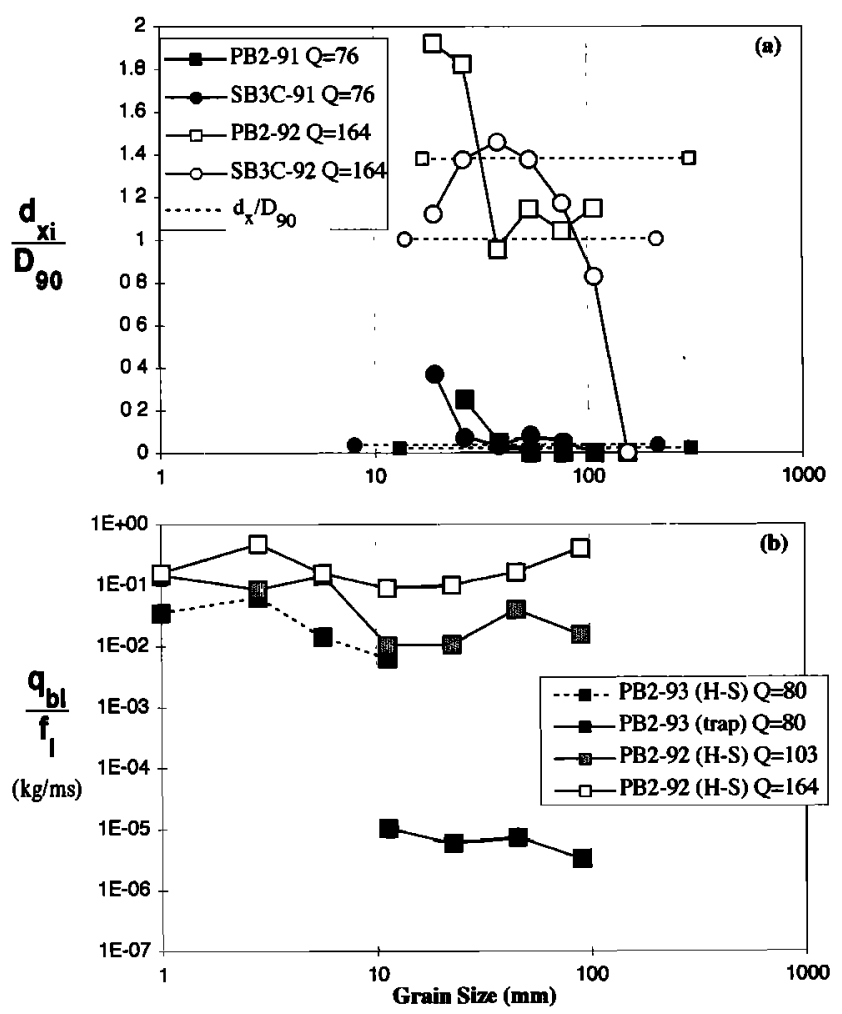

Figure 9. Fractional exchange depths and transport rates as a function of grain size $D_{\mathrm{i}}$. (a) Fractional exchange depth $d_{\mathrm{xi}}$, scaled by $D_{90}$. (b) Fractional transport rates $q_{\text {bi }}$, scaled by proportion in bed $f_{\mathrm{i}}$. Transport rates measured by HelleySmith sampler, with the exception of $D_{\mathrm{i}}>8 \mathrm{~mm}$ at $Q=80$ $\mathrm{m}^{3} / \mathrm{s}$, which were sampled with gravel traps. Both entrainment and transport suggest that the bed sediment behaves as two distinct populations. Sizes coarser than $8 \mathrm{~mm}$ show a much more rapid increase with $Q$ in both $d_{\mathrm{xi}} / D_{90}$ and $q_{\mathrm{bi}} / f_{\mathrm{i}}$.

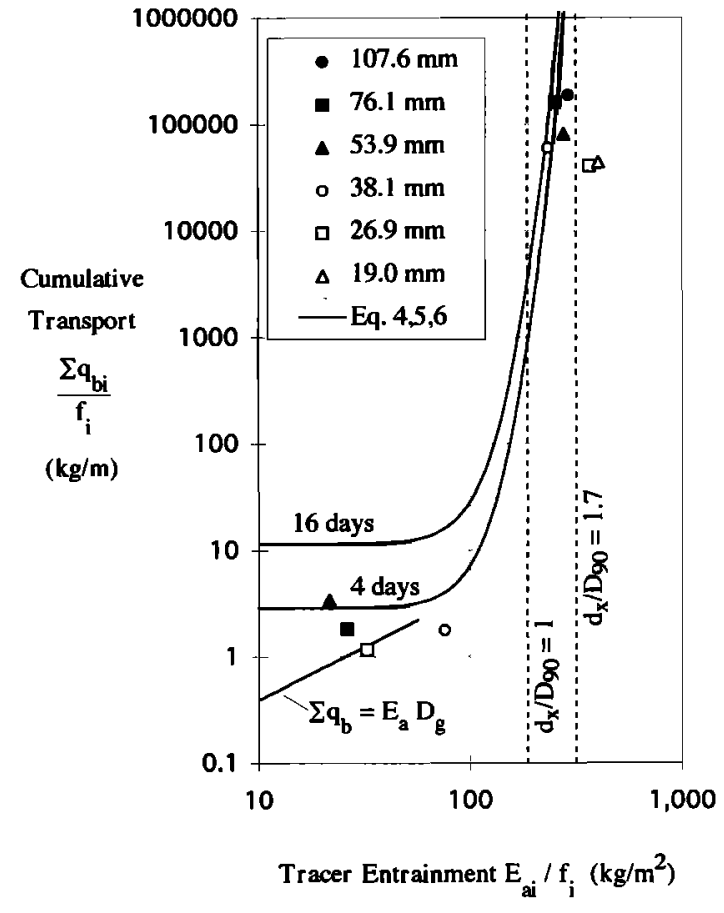

Figure 10. Cumulative fractional transport as a function of tracer gravel entrainment. Curves based on simultaneous solution of (4) and (6) for $E_{\mathrm{a}}$ and (5) for $q_{\mathrm{b}}$, using specified values of $\tau^{*}$. For plane-bed transport, exchange depth approaches a limit on the order of $2 d_{\mathrm{x}} / D_{90}$ at cumulative transport of the order of 100 to $1000 \mathrm{t} / \mathrm{m}$.

$$
E_{\mathrm{a}}=\left(\frac{d_{\mathrm{x}}}{D_{90}}\right) D_{90} \rho_{\mathrm{s}}(1-n)
$$

where $n$ is the bed porosity, taken to be 0.25 , and the values $D_{90}=92 \mathrm{~mm}$ and $\rho_{\mathrm{s}}=2700 \mathrm{~kg} / \mathrm{m}^{3}$ are used; $q_{\mathrm{b}}$ is calculated as a function of $\tau_{0}$ using (5) with $\tau_{\mathrm{r}}=22.5 \mathrm{~Pa} ; \tau^{*}$ is calculated using $D=39 \mathrm{~mm}$, a size slightly larger than $D_{50}$ of the gravel portion of the bed. For a specified $\tau_{0}$, calculation of $\sum q_{\mathrm{b}}$ requires specification of $T$. Two values of $T$ (4 and 16 days) are shown on Figure 10; the smaller value corresponds to the $T$ associated with the smaller values of $E_{\mathrm{a}}$. The apparent effect of $T$ decreases at larger values of $E_{\mathrm{a}}$, for which a large difference in $\tau^{*}$ makes little difference in $d_{\mathrm{x}} / D_{90}$ (Figure $7 \mathrm{a}$ ) and therefore $E_{\mathrm{a}}$.

Although a match is evident between the curves and data on Figure 10, no physical significance is attached to this beyond a claim that the two independent measurements of grain motion are consistent. The variation of $\sum q_{\mathrm{b}}$ with $E_{\mathrm{a}}$ at small transport rates is highly sensitive to the choice of $\tau_{\mathrm{th}}^{*}, \tau_{\mathrm{r}}$, and the value of grain size used to form $\tau^{*}$ in (5). Further, the form of the curves at small $E_{\mathrm{a}}$ is sensitive to the variation of $d_{\mathrm{x}} / D_{90}$ with $\tau^{*}$ near $\tau_{\text {th }}^{*}$, which is not well constrained by the data (Figure $7 \mathrm{a}$ ). Indeed, the plotted relation is likely incorrect in this region because, in the limit of vanishing transport, $\Sigma q_{\mathrm{b}}$ will result from single, rare grain displacements of short length, so that $\Sigma$ $q_{\mathrm{b}}$ will approach $E_{\mathrm{a}}$ multiplied by the length of an individual displacement, which should scale with grain size [Drake et al., 1988]. This is shown as $\Sigma q_{\mathrm{b}}=E_{\mathrm{a}} D_{\mathrm{g}}$ on Figure 10 .

Despite the uncertainty in the relation between $\Sigma q_{\mathrm{b}}$ and $E_{\mathrm{a}}$, the merit of Figure 10 is to show a direct comparison between the two independent measures of grain motion and the empir- 
ical relations representing them. At large $\tau^{*}$ the asymptotic approach to a limiting value of $E_{\mathrm{a}}$ of the order of $300 \mathrm{~kg} / \mathrm{m}^{2}$ is required by (4) and corresponds to $d_{x} / D_{90}=1.7$. Figure 10 also implicitly demonstrates the influence on entrainment of time, which is often not considered in calculations of $\tau_{\mathrm{c}}$ or $Q_{\mathrm{c}}$. If the relation between $\sum q_{\mathrm{b}}$ and $E_{\mathrm{a}}$ is relatively insensitive to $\tau_{0}$, then the magnitude of $E_{a}$ will depend on both $\tau_{0}$ (which determines $q_{\mathrm{b}}$ ) and time (which determines $\Sigma q_{\mathrm{b}}$ ), suggesting that the same degree of entrainment can be produced by different $\tau_{0}$, if the flow duration is suitably chosen. Further, Figure 10 suggests that the influence of time is negligible at large $\Sigma q_{\mathrm{b}}$, for which $E_{\mathrm{a}}$ is a constant, and becomes increasingly important at smaller $\Sigma q_{\mathrm{b}}$.

\section{Summary and Conclusions}

Trial reservoir releases on the Trinity River, California, provided an unusual opportunity to observe gravel entrainment under scheduled conditions of steady flow preceded and followed by very low flows, which permitted access to the river bed. Estimates of local shear stress $\tau_{01}$ were made from observations of local depth-averaged velocity. A large lateral variability in $\tau_{01}$ was observed, even for sections of relatively simple, trough-like geometry in a nearly straight reach. More critically, the variation of $\tau_{01}$ with discharge differed from that of the section-average $\tau_{0}$, demonstrating that the latter cannot be modified by a simple coefficient to give $\tau_{01}$ and therefore estimate local entrainment and transport.

Large tracer gravel installations that incorporated the bed surface and subsurface were used to measure the entrained proportion of the bed surface, the entrainment of individual grain sizes, and the depth of scour. A scaled exchange depth, $d_{\mathrm{x}} / D_{90}$, was found to vary consistently with a Shields parameter $\tau_{g}^{*}$ defined using $\tau_{01}$ and the median size of the gravel fraction of the bed material. A threshold value of $\tau_{g}^{*}, \tau_{\mathrm{th}}^{*} \approx$ 0.031 is associated with the onset of measurable entrainment. $d_{\mathrm{x}} / D_{90}$ increases rapidly at small $\tau_{g}^{*} / \tau_{\mathrm{th}}^{*}$ and asymptotically approaches a limiting value of $\approx 1.7$ at large $\tau_{g}^{*}$, suggesting a limiting exchange depth for plane-bed transport of slightly less than $2 D_{90}$. Mean entrainment to the base of the bed surface layer, $d_{x} / D_{90} \approx 1$, occurs at $\tau_{g}^{*} \approx 0.035$, a typical value for incipient motion in well-controlled experiments in smaller channels.

The transition from complete immobility to entrainment of the entire surface occurs over a narrow range of $\tau_{g}^{*}$ of the order of $10-15 \%$. This range is characterized by partial transport, in which only a portion of the grains of a given size on the bed surface are mobile. For $d_{x} / D_{90}>0.1$, all sizes are entrained and fractional exchange depths fall within a factor of 2 , with the larger sizes tending to have the smallest entrainment.

Transport rates were measured with gravel traps for one flow with small transport rates and with bed load samplers at three discharges. Different transport relations are observed for the fine and coarse portions of the bed using a size boundary of $8 \mathrm{~mm}$, which corresponds approximately to the threshold between matrix and framework sizes in the bed. Measurable gravel transport begins at a higher $\tau_{0}$ than that for sand, increases more rapidly with $\tau_{0}$, and reaches comparable transport rates at $\tau_{0}$ approximately $70 \%$ larger than that producing the onset of measurable gravel entrainment.

Gravel transport rates can be represented by the Parker [1979] transport relation, the only fitted parameter for which is the reference shear stress, a surrogate for the critical shear stress for incipient motion. A dimensionless reference shear stress of $\tau_{\mathrm{r} g}^{*}=0.039$, which is consistent with observations of $\tau_{\mathrm{r}}^{*}$ in smaller channels, was determined using very small transport rates observed in the gravel traps.

Observations of entrainment and transport were found to be consistent and provide an indication of the degree of entrainment associated with small transport rates. Both entrainment and transport rates for the gravel fractions drop to essentially zero for $\tau_{0} / \tau_{\text {ri }}$ on the order of 0.85 to 0.9 , as is suggested by the form of the Parker [1979] transport relation. In the region $0.85<\tau_{0} / \tau_{\text {ri }}<1.0$, a state of partial transport exists, and both $d_{\mathrm{x}} / D_{90}$ and $q_{\mathrm{bi}} / f_{\mathrm{i}}$ increase very rapidly with $\tau_{0}$. The reference transport value of $\tau_{g}^{*}$ corresponds to grain exchange to a depth slightly greater than $D_{90}$ and is associated with entrainment of all grain sizes, with partial transport evident for the coarsest fractions. Two entirely different measures of incipient motion (mean scour to a depth of $\approx D_{90}$ and the reference transport rate) are observed to occur at nearly the same flow.

Acknowledgments. This study was funded by the U.S. Fish and Wildlife Service (USFWS), Trinity River Flow Study, under cooperative agreements with the Johns Hopkins University (14-16-0001-91514) and the University of California (14-16-0001-91515), the latter administered by the Center for Environmental Design Research. Additional funding was provided by the Southern California Edison Company and by an award for Research Excellence from the Pacific Gas and Electric Company administered by the University of California Center for Water and Wildland Resources. Much of our field work would not have been possible without the invaluable advice and support of Andy Hamilton, Paul Zedonis, Randy Brown, and Mark Hampton of the USFWS. The USFWS office in Weaverville, California, provided useful information for our study, as did Trinity Restoration Associates in Arcata, California. The field work required considerable assistance and dedicated cooperation from a large group: Tom Benjamin, Stuart Cook, Danielle DeClercq, Brendan DeTemple, Gary Fleener, Jennifer Gilson, Ashley Goldhor-Wilcock, Paul Harper, Bette Kim, Kallie Kull, Don Parrish, Janet Parrish, Mark van Steeter, Becky Thomas, Barbara Walker, and Jack Wallace. Review comments by Roger Kuhnle and Tom Lisle improved the clarity and accuracy of the text.

\section{References}

Andrews, E. D., Entrainment of gravel from naturally sorted riverbed material, Geol. Soc. Am. Bull., 94, 1225-1231, 1983.

Ashworth, P. J., and R. I. Ferguson, Size-selective entrainment of bed load in gravel bed streams, Water Resour. Res., 25, 627-634, 1989.

Carling, P. A., Threshold of coarse sediment transport in broad and narrow natural streams, Earth Surf. Processes Landforms, 8, 1-18, 1983.

Church, M., J. F. Wolcott, and W. K. Fletcher, A test of equal mobility in fluvial sediment transport: behavior of the sand fraction, Water Resour. Res., 27, 2941-2951, 1991.

Drake, T. G., R. L. Shreve, W. E. Dietrich, P. J. Whiting, and L. B. Leopold, Bedload transport of fine gravel observed by motionpicture photography, J. Fluid Mech., 192, 193-217, 1988.

Gomez, B., Temporal variation in bedload transport rates: The effect of progressive bed armoring, Earth Surf. Processes Landforms, 8, 41-54, 1983.

Gomez, B., Bedload transport and changing size distributions, in Changing River Channels, edited by A. Gurnell and G. Petts, pp. 177-199, John Wiley, New York, 1995.

Gomez, B., R. L. Naff, and D. W. Hubbell, Temporal variation in bedload transport rates associated with the migration of bedforms, Earth Surf. Processes Landforms, 14, 135-156, 1989.

Iseya, F., and H. Ikeda, Pulsations in bedload transport rates induced by a longitudinal sediment sorting: A flume study using sand and gravel mixtures, Geogr. Ann., 69(A), 15-27, 1987.

Komar, P. D., Selective grain entrainment by a current from a bed of mixed sizes: A reanalysis, J. Sediment. Petrol., 57(2), 203-211, 1987. Kuhnle, R. A., Fractional transport rates of bedload on Goodwin Creek, in Dynamics of Gravel-bed Rivers, edited by P. Billi, R. D. 
Hey, C. R. Thorne, and P. Tacconi, pp. 141-155, John Wiley, New York, 1992.

Kuhnle, R. A., and J. B. Southard, Bed load transport fluctuation in a gravel bed laboratory channel, Water Resour. Res., 24, 247-260, 1988.

McArdell, B. W., and P. R. Wilcock, Laboratory observations of grain mobility in a poorly sorted sand-gravel sediment, Eos Trans. AGU, 75(16), Spring Meet. Suppl., 182, 1994.

McNeil, W. J., and W. H. Ahnell, Measurement of gravel composition of salmon stream beds. Circ. 20, Univ. of Wash. Fish. Res. Inst., Seattle, 1960.

Parker, G., Hydraulic geometry of active gravel rivers, J. Hydraul. Div. Am. Soc. Civ. Eng., 105(HY9), 1185-1201, 1979.

Parker, G., and P. C. Klingeman, On why gravel bed streams are paved, Water Resour. Res., 18, 1409-1423, 1982.

Parker, G., P. C. Klingeman, and D. L. McLean, Bedload and size distribution in paved gravel-bed streams, J. Hydraul. Div. Am. Soc. Civ. Eng., 108(HY4), 544-571, 1982.

Pitlick, J., Variability of bed load measurement, Water Resour. Res., 24, 173-177, 1988.

Wathen, S. J., R. I. Ferguson, T. B. Hoey, and A. Werrity, Unequal mobility of gravel and sand in weakly bimodal river sediments, Water Resour. Res., 31, 2087-2096, 1995.

Whiting, P. J., and W. E. Dietrich, Boundary shear stress and roughness over mobile alluvial beds, J. Hydraul. Eng., 116(12), 1495-1511, 1990.

Wilcock, P. R., Methods for estimating the critical shear stress of individual fractions in mixed-size sediment, Water Resour. Res., 24, 1127-1135, 1988.

Wilcock, P. R., Flow competence: A criticism of a classic concept, Earth Surf. Processes Landforms, 17(3), 289-98, 1992a.

Wilcock, P. R., Experimental investigation of the effect of mixture properties on transport dynamics, in Dynamics of Gravel-bed Rivers, edited by P. Billi, R. D. Hey, C. R. Thorne, and P. Tacconi, pp. 109-139, John Wiley, New York, 1992b.

Wilcock, P. R., The critical shear stress of natural sediments, J. Hydraul. Eng., 119(4), 491-505, 1993.

Wilcock, P. R., Estimating local bed shear stress from velocity observations, Water Resour. Res., in press, 1996.
Wilcock, P. R., and B. W. McArdell, Surface-based fractional transport rates: Mobilization thresholds and partial transport of a sand-gravel sediment, Water Resour. Res., 29, 1297-1312, 1993.

Wilcock, P. R., and J. B. Southard, Experimental study of incipient motion in mixed-size sediment, Water Resour. Res., 24, 1137-1151, 1988.

Wilcock, P. R., A. F. Barta, and C. C. Shea, Estimating local bed shear stress in large gravel-bed rivers, in Proceedings, Hydraulic Engineering '94 Conference, Buffalo, edited by G. V. Cotroneo and R. R. Rumer, pp. 834-838, Am. Soc. of Civ. Eng., New York, 1994.

Wilcock, P. R., G. M. Kondolf, A. F. Barta, W. V. G. Matthews, and C. C. Shea, Spawning gravel flushing during trial reservoir releases on the Trinity River: Field observations and recommendations for sediment maintenance flushing flows, final report to the U.S. Fish and Wildlife Serv., Trinity River Flow Study, Lewiston, Calif., Feb. 1995.

Wilcock, P. R., G. M. Kondolf, W. V. G. Matthews, and A. F. Barta, Specification of sediment maintenance flows for a large gravel-bed river, Water Resour. Res., this issue.

Yalin, M. S., Mechanics of Sediment Transport, Pergamon, New York, 1977.

A. F. Barta, Intermountain Research Station, U.S. Forest Service, 316 E. Myrtle St., Boise, ID 83702. (e-mail: sediment@micron.net)

G. M. Kondolf and W. V. G. Matthews, Center for Environmental Design Research, University of California, 390 Wurster Hall, Berkeley, CA 94720. (e-mail: kondolf@ced.berkeley.edu)

J. Pitlick, Department of Geography, University of Colorado, Boulder, CO 80302.

C. C. Shea, Parsons Brinckerhoff, Inc., 301 N. Charles St., Baltimore, MD 21201.

P. R. Wilcock, Department of Geography and Environmental Engineering, The Johns Hopkins University of Baitimore, MD 21218. (e-mail: wilcock@jhuvms.hcf.jhu.edu)

(Received February 5, 1996; revised May 20, 1996; accepted May 24, 1996.) 